\title{
A Research on Wind Tunnel on Drag Reduction in Aircraft Wing by Inducing Surface Roughness
}

\author{
Rohith Indulekha Janardhanan, Ajith Raj Rajendran, Dev Anand, Prakash
}

\begin{abstract}
Drag is a major issue that aircraft industries are facing today. Innumerable investigations are in progress which mainly focus on the methods to reduce drag. Improving the aerodynamic efficiency of the vehicle can resolve this drawback to a great extent. The aerodynamic efficiency is explained in $L / D$ ratio, decreasing the drag component will increase the aerodynamic efficiency. In this research a methodology to reduce the drag by creating roughness over wing surface has been adopted. By adopting this surface roughness method, the transition of the air flow from the laminar to the turbulent region will result in less drag. This research is being carried out based on the above said theory. The outcome of this method can delay the flow separation in a wing which helps in increasing the lift. The roughness has reduced the coefficient of skin friction drag or viscous drag and increased the coefficient of lift along with the stall angle of attack. NACA 0012 airfoil was selected for this study. Aluminum wing models are fabricated with and without surface roughness and same has been tested in Wind Tunnel. The results are discussed in terms of Lift and Drag.
\end{abstract}

Keywords--- Aircraft Wing, Drag Reduction, Surface Roughness, Wind Tunnel, Coefficient of Lift and Drag.

\section{INTRODUCTION}

The only means of transportation during the earlier stages of human civilization was his legs. Gradually, we have achieved faster and more luxurious ways of travelling, latest being the air transport. Since, its invention airplanes have been getting more and more popularity as it is the fastest mode of transportation available. It has also gained popularity as a war machine since World War II. This popularity of air transport has led to many new inventions and research to develop faster and more economical planes. This project is such an attempt to determine how we can derive maximum performance in a wing.[1] The aerodynamic efficiency of a wing is explained in terms of $\mathrm{L} / \mathrm{D}$ ratio. An airfoil is a cross-section of wing designed to develop lift to an airplane during takeoff and while in flight. But, this same process which keeps the aircraft in flight will also create an opposing force called the Drag. This drag is mainly because of the frictional force developed on the surface of the wing. To attain better aerodynamic efficiency the frictional drag developed on the wing has to be reduced which in turn will give better L/D ratio.[1]In this work, we

Revised Manuscript Received on July 10, 2019.

Rohith Indulekha Janardhanan, Department of Aeronautical Engineering, Noorul Islam University, Kumaracoil, Kanyakumari, T.N India. (e-mail: ijrohith1992@gmail.com)

Ajith Raj Rajendran, Department of Aeronautical Engineering, Noorul Islam University, Kumaracoil, Kanyakumari, T.N, India.

(e-mail: ajithraj006@gmail.com)

Dev Anand, Director- Research, Noorul Islam University, Kumaracoil, Kanyakumari, T.N, India.

Prakash, Department of Aeronautical Engineering, Noorul Islam University, Kumaracoil, Kanyakumari, T.N, India. have implemented surface roughness on a NACA 0012 airfoil to reduce the frictional drag by eliminating the wake formation. Wake formation is delayed or nullified by altering the flow separation, thus increasing the L/D ratio.[2]

\section{DESIGN OF WING}

I. Design of wing with and without Surface Roughness

NACA 0012 airfoil has been selected for this study which is a symmetrical airfoil. Symmetric airfoil is the one in which both the camber line and the chord line coincide each other.[3] Wing models with and without Surface Roughness are created using CATIA V5 software.

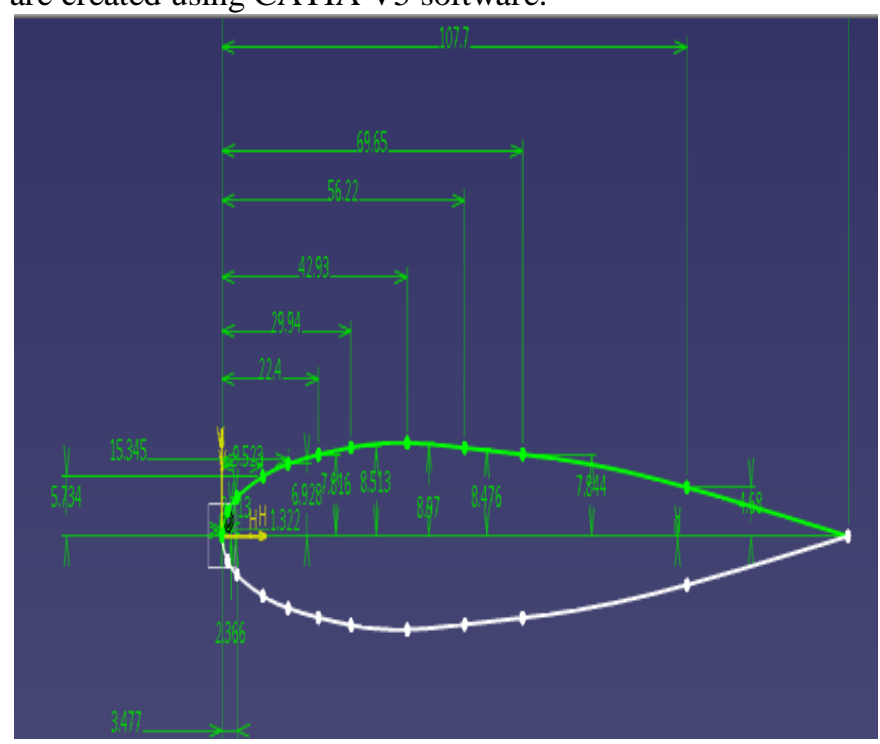

Fig. 1: 2D view of NACA 0012 airfoil

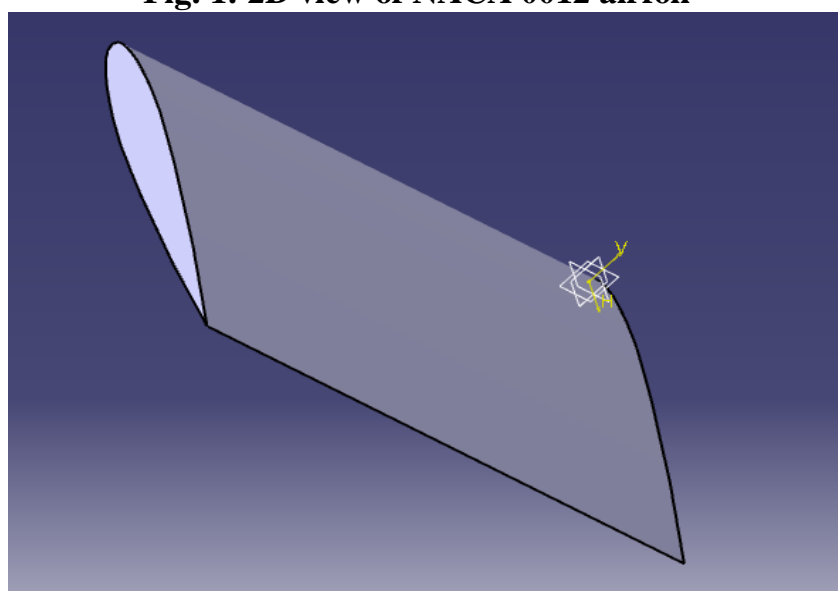

Fig. 2: 3D view of NACA 0012 airfoil without roughness

Published By: Blue Eyes Intelligence Engineering 


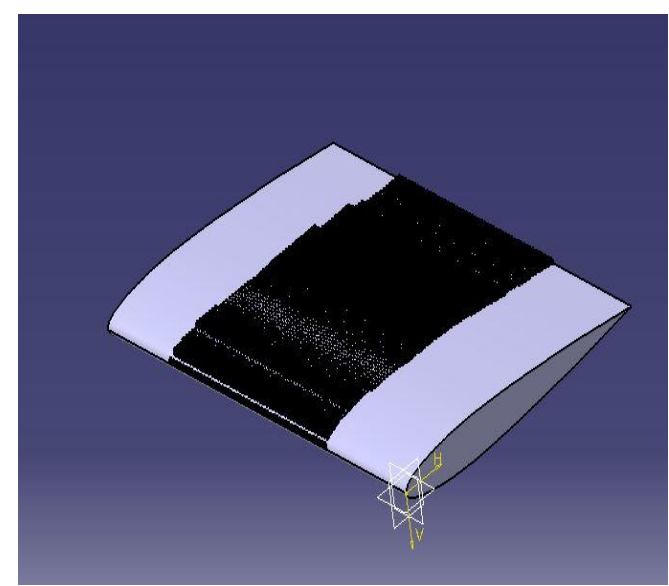

Fig. 3: 3D view of NACA 0012 airfoil without roughness

\section{FABRICATION}

The above designed wing models are fabricated with $\mathrm{Al}$ 6061-T6 Sheet. Al 6061-T6 alloy is the most common grade of Aluminum used in aircraft construction because of its good machinability and weldability. Therefore, this alloy is selected for the fabrication of wing for our study. Surface roughness is created by gluing sand paper over the surface of the wing.

\section{A. Mechanical properties of Al 6061-T6 Sheet}

$\begin{array}{ll}\text { Modulus of Elasticity } & : 68.9 \mathrm{GPa} \\ \text { Ultimate Bearing Strength } & : 607 \mathrm{MPa} \\ \text { Poisson's Ratio } & : 0.33 \\ \text { Fatigue Strength } & : 6.5 \mathrm{MPa} \\ \text { Shear Strength } & : 207 \mathrm{MPa} \\ \text { Density } & : 2.7 \mathrm{~g} / \mathrm{cc}\end{array}$

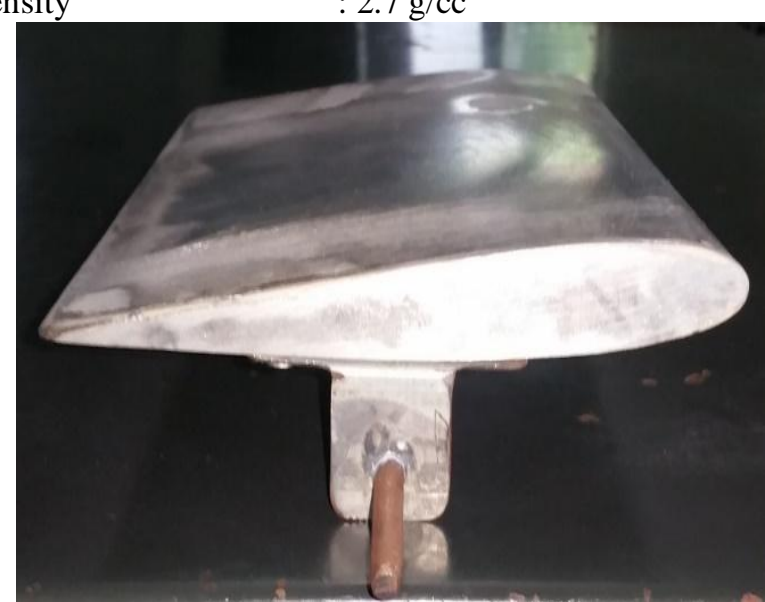

Fig. 4: Fabricated wing model without roughness

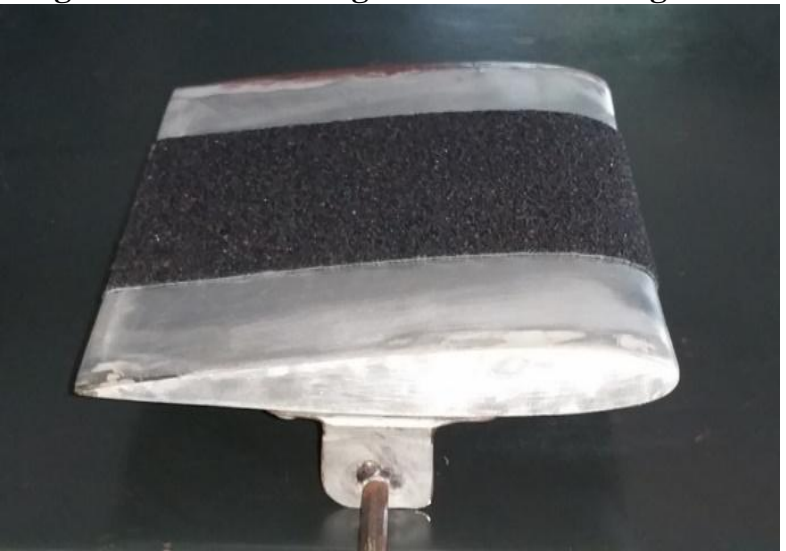

Fig. 5: Fabricated wing model with roughness

\section{B. Aspect Ratio}

The aspect ratio of the fabricated wing is calculated.

$$
\begin{gathered}
\mathrm{AR}=\frac{b^{2}}{s} \\
\mathrm{~b}=19.7 \mathrm{~cm} \\
\mathrm{~S}=19.7 \times 14.5 \\
=285.65 \mathrm{~cm}^{2} \\
\mathrm{AR}=\frac{19.7^{2}}{285.65}=1.35
\end{gathered}
$$

\section{EXPERIMENT \& RESULTS}

The present research is to study and compare the aerodynamic efficiency of the fabricated NACA 0012 airfoils with and without roughness at various angle of attack using a subsonic wind tunnel.

\section{A. Theory of Wind Tunnels}

A wind tunnel is a tool used in aerodynamic research which provides airstream flowing under controlled conditions so that the models inserted can be tested. Aerodynamic and pressure forces are measured using various Lift- Drag sensors and U tube manometer.[4]

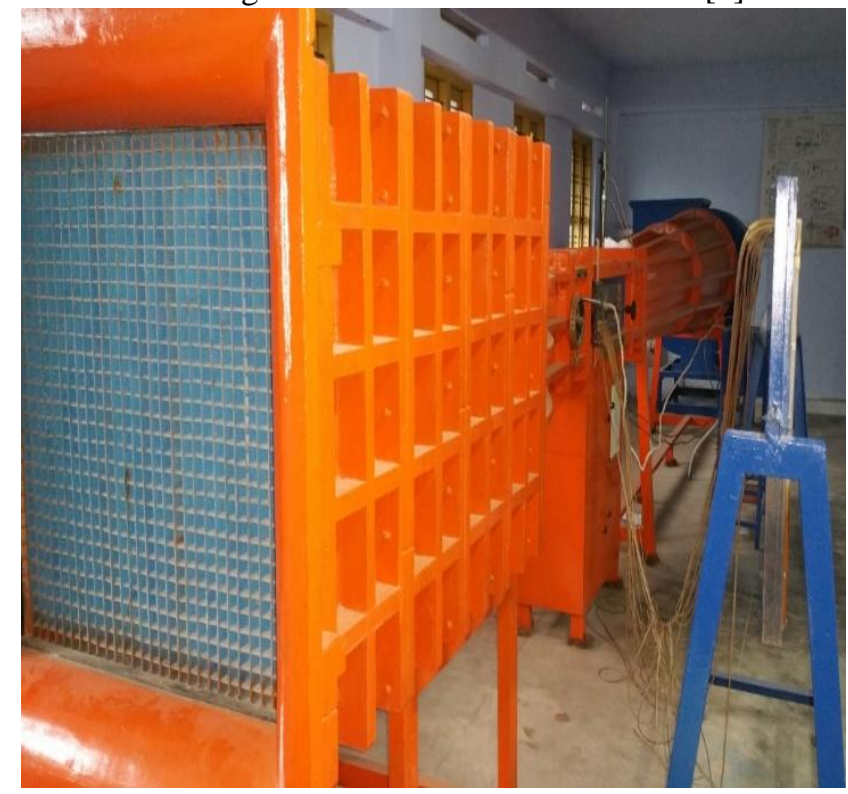

Fig. 6: Subsonic wind tunnel

\section{B. Specification of Wind Tunnel used}

Test Section $\quad: 0.3 \times 0.3 \mathrm{~m}$

Air speed : maximum of $70 \mathrm{~m} / \mathrm{s}$

Overall size $\quad: 6 \mathrm{~m}$

Power required $\quad: 7.5 \mathrm{HP}$ motor with $900 \mathrm{rpm}$

$C$. Testing of wing without surface roughness

Lift equation is:

Drag equation is:

$$
\begin{gathered}
L=\frac{1}{2} \rho v^{2} S C_{L} \\
C_{L}=\frac{2 L}{\rho V^{2} S C_{L}}
\end{gathered}
$$

$$
\begin{gathered}
D=\frac{1}{2} \rho v^{2} S C_{D} \\
C_{D}=\frac{2 D}{\rho V^{2} S C_{D}}
\end{gathered}
$$

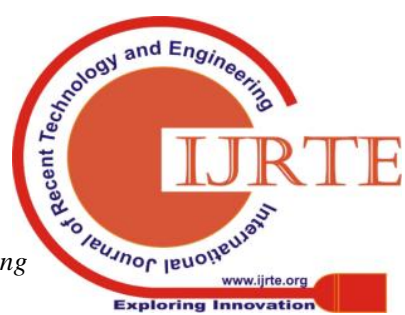




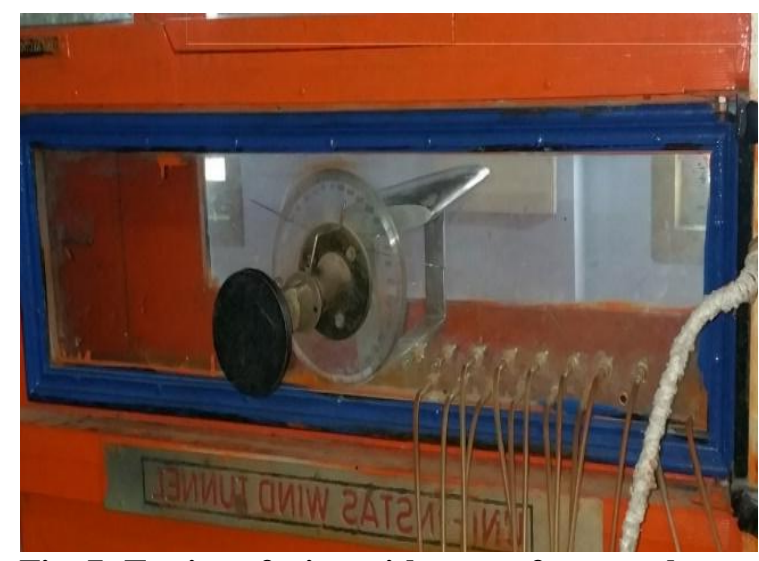

Fig. 7: Testing of wing without surface roughness

Table I: Lift ad Drag values for wing without roughness

\begin{tabular}{|c|c|c|c|c|c|}
\hline $\begin{array}{c}\text { Angle of } \\
\text { attack } \alpha\end{array}$ & $\begin{array}{c}\text { Lift } \\
\text { L }\end{array}$ & $\begin{array}{c}\text { Drag } \\
\mathbf{D}\end{array}$ & $\begin{array}{c}\text { Coefficient } \\
\text { of Lift } \\
\mathbf{C}_{\mathbf{L}}\end{array}$ & $\begin{array}{c}\text { Coefficient of } \\
\text { Drag } \\
\mathbf{C}_{\mathbf{D}}\end{array}$ & $\mathbf{C}_{\mathbf{L}} / \mathbf{C}_{\mathbf{D}}$ \\
\hline 2 & 23.94 & 10.26 & 0.0028 & 0.0012 & 2.3 \\
\hline 4 & 36.78 & 13.68 & 0.0043 & 0.0016 & 2.69 \\
\hline 6 & 55.59 & 14.5 & 0.0065 & 0.0017 & 3.82 \\
\hline 8 & 76.12 & 16.25 & 0.0089 & 0.0019 & 4.7 \\
\hline
\end{tabular}

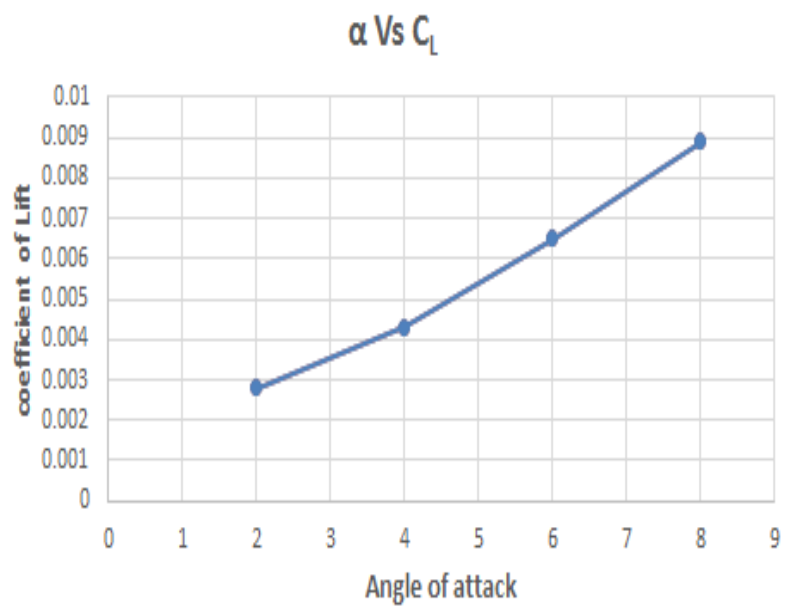

Fig. 7 Angle of Attack Vs Coefficient of Lift

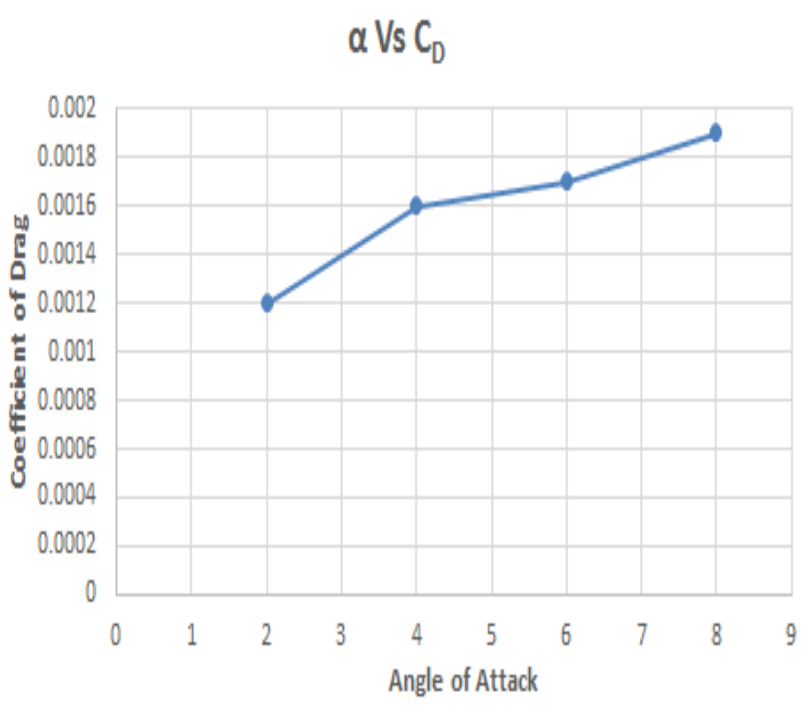

Fig. 8: Angle of Attack Vs Coefficient of Drag

\section{Testing of wing with surface roughness}

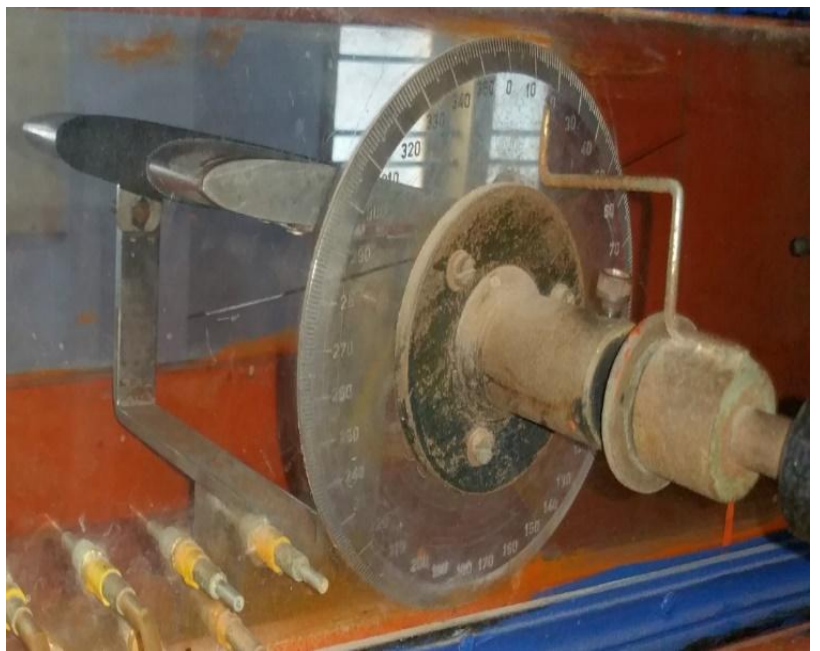

Fig. 9: Testing of wing with surface roughness

Table 2: Lift ad Drag values for wing with roughness

\begin{tabular}{|c|c|c|c|c|c|}
\hline $\begin{array}{c}\text { Angle } \\
\text { of } \\
\text { attac } \\
\mathbf{k} \\
\boldsymbol{\alpha}\end{array}$ & $\begin{array}{c}\text { Lift } \\
\mathbf{L}\end{array}$ & $\begin{array}{c}\text { Drag } \\
\mathbf{D}\end{array}$ & $\begin{array}{c}\text { Coefficien } \\
\mathbf{t} \text { of Lift } \\
\mathbf{C}_{\mathrm{L}}\end{array}$ & $\begin{array}{c}\text { Coefficien } \\
\mathbf{t} \text { of Drag } \\
\mathbf{C}_{\mathrm{D}}\end{array}$ & $\begin{array}{c}\mathrm{C}_{\mathrm{L}} / \mathrm{C} \\
\mathbf{D}\end{array}$ \\
\hline 2 & 22.2 & 5.90 & 0.0026 & 0.00069 & 3.76 \\
\hline 4 & $\begin{array}{c}35.0 \\
6\end{array}$ & 5.98 & 0.0041 & 0.00070 & 5.86 \\
\hline 6 & 52.1 & 7.61 & 0.0061 & 0.00089 & 6.85 \\
\hline 8 & 83.8 & 11.1 & 0.0098 & 0.0013 & 7.5 \\
\hline 2 & 1 & & & \\
\hline
\end{tabular}

\section{a Vs $C_{L}$}

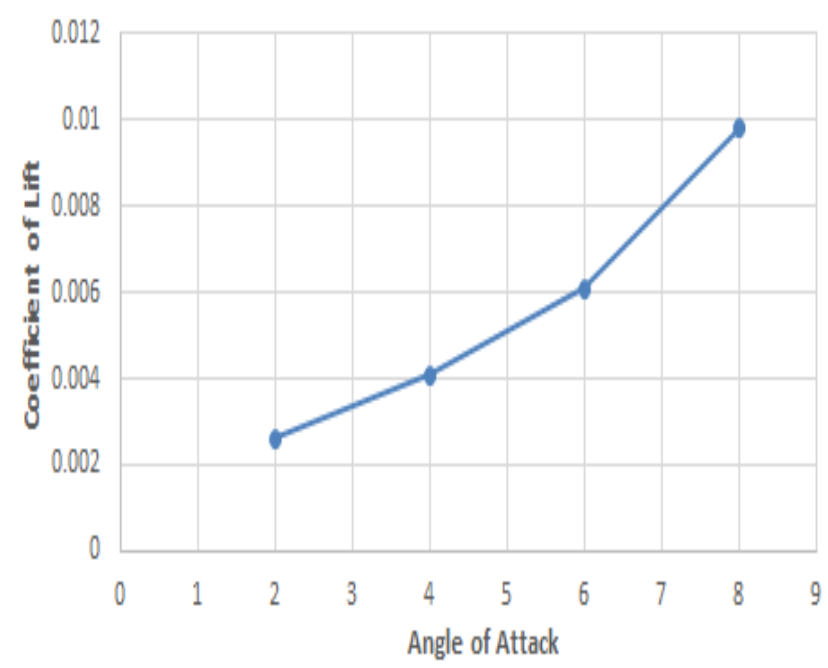

Fig. 10: Angle of Attack Vs Coefficient of Lift

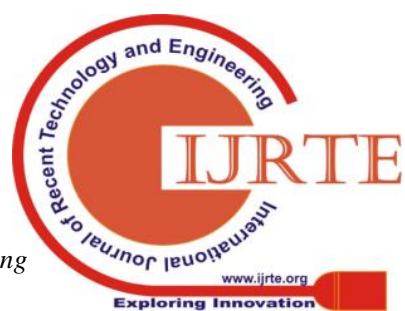




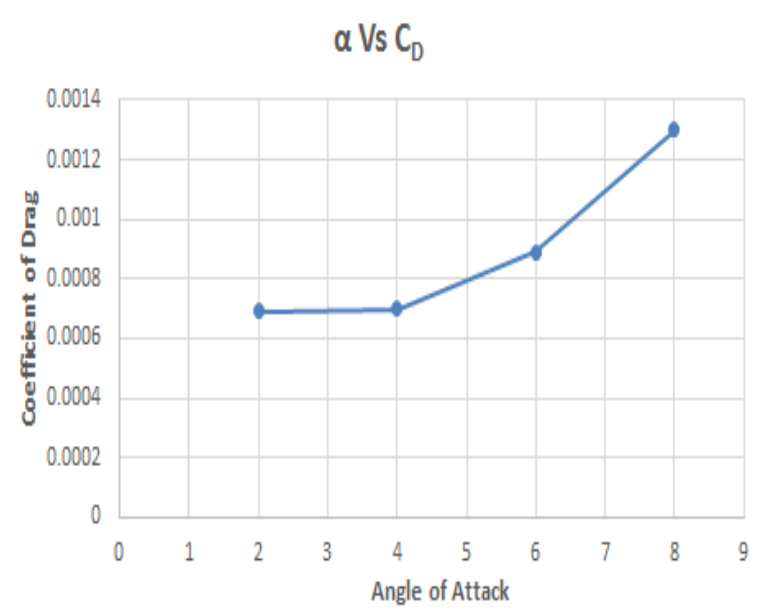

Fig. 11: Angle of Attack Vs Coefficient of Drag

\section{COMPARISON}

\section{$\alpha$ vs $C L / C D$}

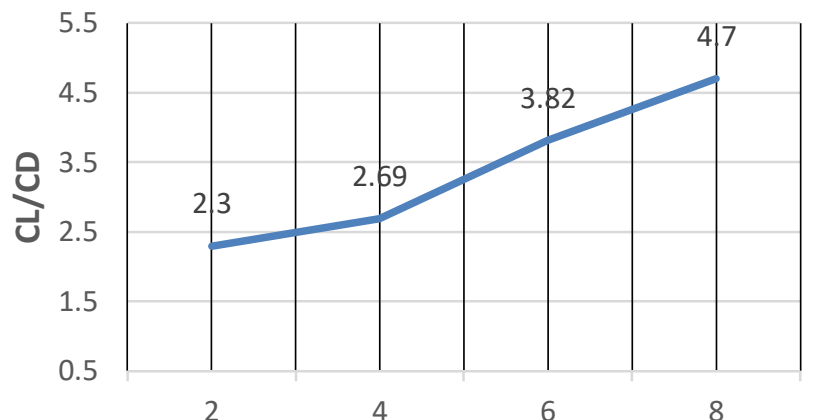

Angle of Attack

Fig. 12: CL/CD ration for wing without roughness

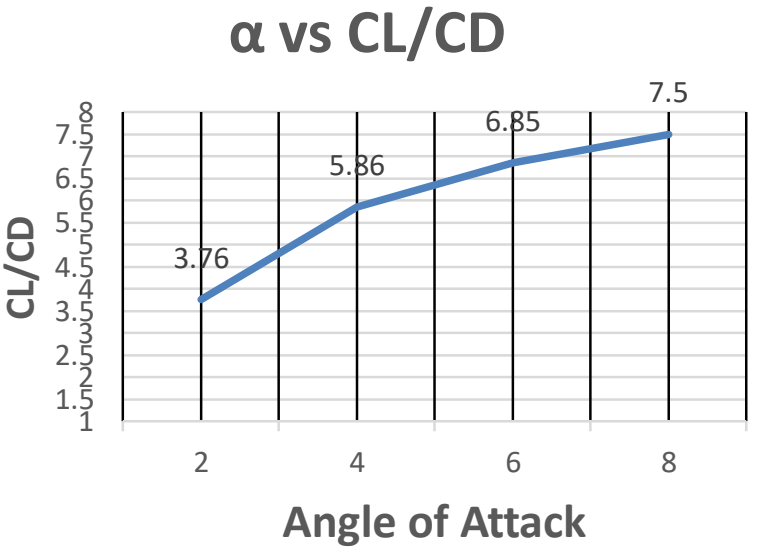

Fig. 13: CL/CD ration for wing with roughness

Comparing the above results of wings with and without roughness, we observed a reduction in drag formation in the wing with surface roughness. This reduction in drag improved the $\mathrm{CL} / \mathrm{CD}$ ratio which in turn augments the aerodynamic efficiency of the wing.

\section{CONCLUSION}

Experimental investigation has been carried out in a Wind Tunnel with fabricated Aluminum wing models with and without surface roughness. When we compare the $\mathbf{C}_{\mathbf{L}} / \mathbf{C}_{\mathbf{D}}$ values of wings with and without roughness, the skin friction drag for the wing with surface roughness is reduced thus giving an increased value of $\mathbf{C}_{\mathbf{L}} / \mathbf{C}_{\mathbf{D}}$ ratio. Therefore, from the above wind tunnel experiment it is proved that, adding surface roughness over the wing surface can considerably improve the aerodynamic efficiency of the wing by reducing the skin friction drag.

\section{REFERENCES}

1. R. Jones and D.H. Williams, Effect of surface roughness on characteristics ofairfoil NACA and RAF 34,1936.

2. John A, Zalovcik and Clotaire Wood, A Flight investigation on the Effect of Surface Roughness on Wing Profile Drag with Transition Fixed, 1944.

3. KousikKumaar. R and P. Maniiarasan, Reduction of Skin Friction Drag in Wings byEmploying Riblets, 2015.

4. Ishan.M. Shah, S. A. Thakkar, K. H. Thakkar and Bhavesh A. Patel, Performance Analysis on Airfoil Model in Wind Tunnel Testing Machine (WTTM), 2013. 